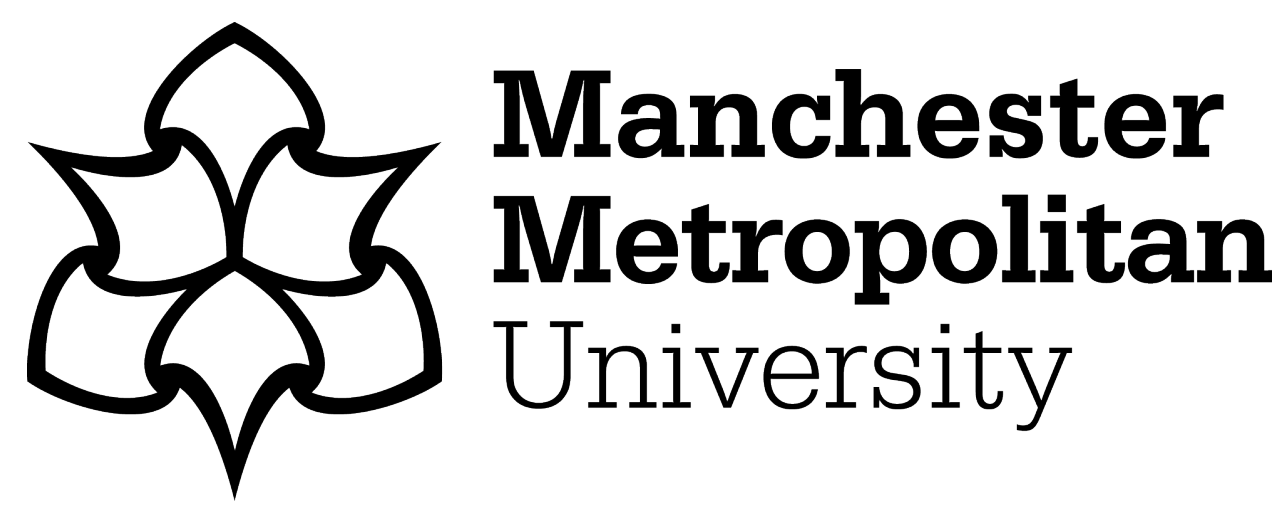

El-Abani, Suaad M, Jacobs, Susie, Chadwick, Kathryn and Arun, Shoba (2020) Migration and attitudes towards domestic violence against women: a case study of Libyan migrants in the UK. Migration and Development, 9 (1). pp. 111-130. ISSN 2163-2324

Downloaded from: https://e-space.mmu.ac.uk/622017/

Version: Accepted Version

Publisher: Taylor and Francis

DOI: https://doi.org/10.1080/21632324.2018.1504199

Please cite the published version 


\title{
Migration and Attitudes towards Domestic Violence against Women: a case study of Libyan migrants in the UK
}

\section{Suaad El-Abani, Susie Jacobs ${ }^{1}$, Kathryn Chadwick, and Shoba Arun}

\begin{abstract}
This article analyses attitudes to DVAW (Domestic Violence against Women) among Libyan migrants in the north of England; this is the first such study among Libyan migrants. One hundred seventy-five (175) respondents were interviewed in a questionnaire survey and 20 in semi-structured interviews. Migrant status has been identified as an important marker or precarity; gendered and racialized experiences deepen structural forms of insecurity. The research explored the impact of migration on participants' attitudes to DVAW. The concepts of gender regime and gender order, additionally, help to provide a framework for understanding of the multifaceted nature of (unequal) gender relations within Libyan Arab communities. The study found that gender and educational level were the most important variables associated with views about DVAW within the sample, whereas length of stay in the UK was not statistically associated with attitudes towards DVAW. The article explores reasons for relative continuity in beliefs about DVAW in the context insecurities of migration. Despite continuities, shifts and changes are taking place in many women's lives.
\end{abstract}

Keywords: Domestic Violence Against Women (DVAW); Libyan migrants; gender regimes and gender orders; insecurity and precarity.

${ }^{1}$ Corresponding author/ contact: Susie Jacobs-- s.jacobs@mmu.ac.uk 


\section{Introduction:}

This article discusses attitudes to DVAW (Domestic Violence against Women) among a sample of Libyan migrants in the north of England. DVAW is one of the most prevalent of human rights abuses (Bharani, 2013). UN Women estimates that at least $35 \%$ of women have suffered physical and/or sexual intimate partner violence or sexual violence by a non-partner, with some studies indicating rates of $70 \%$ (UNWomen, 2017; Watts and Zimmerman, 2002). DVAW harms women, affects their health and reinforces other forms of violence and inequality throughout society (Scott and McManus, 2016; Walby, 2005). As is widely acknowledged (Hunnicott, 2009; Walby, 2010), violence against women is rooted within wider systems of gender subordination and stratification, as well as within socio-economic and racialized hierarchies (Crenshaw, 1991; Sokoloff and Dupont, 2005). Studies of DVAW among migrant women indicate that migrants' frames of reference usually refer both to their societies/ countries of origin and to the country of settlement (Menjívar and Salcido, 2002; Bhuyan et al., 2005). Thus, studies of DVAW within Arab societies and among (various) migrant communities are both of relevance to interpretation of this study.

Numerous studies have been conducted on the issue of domestic violence, but most have been conducted within Western societies. No comprehensive or largescale studies of DVAW exist within Libya, and domestic or intimate partner violence is not criminalised to date. Smallscale studies have, however been carried out within Libya. Allteer (1997), for instance, interviewed 55 Libyan housewives to ascertain patterns of DVAW. Alkkly (2005) drew attention to the fact that domestic violence is the most common context of VAW amongst Libyan women, but emphasised this is a difficult field for data collection as most cases are not reported to the police. Similarly, Awaz (2010) reported that sexual violence is often viewed as shameful and hence under-reported by Libyan women. Studies by Human Rights Watch (HRW, 2006; 2013) based on interviews conducted in Tripoli and Benghazi, stated that there is a widespread denial 
that DVAW exists in Libya, and lack of adequate laws and services, leaves victims of violence without an effective remedy and deters reporting of offences. A further study documenting the findings of the Libya Status of Women Survey (Abdul-Latif, 2013) on opinions and attitudes toward domestic violence, indicate a relatively high level of acceptance of domestic violence in Libyan society by women and men, but men to a greater extent.

Research on domestic and gender violence among Arab and neighbouring countries is relatively limited. Largescale surveys in Egypt (El-Zanaty et al. 1996) and Tunisia (Douki et al. 2003), however, found prevalence rates of 33-34\%. Another 2005 Egyptian study of 5450 women found that half justified DVAW, with this finding most marked for rural women (Yount, 2009). Haj-Yahia researched DVAW very widely in Arab societies. As one example, among Palestinan refugees in Jordan he found that $80 \%$ of men and women in the study stated that abuse of the wife would not justify reporting the husband to police (Haj-Yahia 1998). In a Saudi Arabian sample of 230 (Almosaed, 2004), 30\% of men said they had physically abused female family members and $41 \%$ of the sample said female relatives had been victims of physical violence. In Iran, Tizro (2012) found that half of husbands surveyed said that they used physical violence to control their wife/ves.

Research on DVAW among migrant communities - mainly to Western countries - is also limited and many are US-based, but this is a growing field (see later discussion). Studies have found that characteristics of the migrant situation are relevant to migrating women across a range of cultures and contexts. Such factors influence experiences of and attitudes to DVAW: these include economic dependence; isolation; legal [immigration] status; language facility and community pressures (Bhuyan and Senturia, 2005; Raj and Silverman, 2005). Thus, insecurity and precarity (Standing, 2014) often frame migrants' lives, and this is often particularly the case for women. 
Migrant status has been identified as an important additional marker for precarity, which may be distinguishable from women's previous experiences of insecurity within home countries (See Piper et al. 2017). Further, studies show that immigrant women's lives are often characterised by high levels of risk. The connection between gender inequalities, structural inequalities, interpersonal power relations, norms of masculinity, and men's perpetration of various types of violence has long been noted (Kaufman 1987; Connell, 1995). Such gendered and racialised experiences deepen structural forms of precarious social relations, with insecure situations existing within homes, workplaces (Premji et al 2017) and wider society. Research has also noted changing household power relations and divisions of labour with migration (Hibbins 2005). This 'hyper-precarity' poses a challenge for understanding and responding to different forms of gender relations, particularly domestic violence within migrant households. For example, research exists on how immigrant household members who suffer gender-based violence face particular challenges in accessing health services, social support, and knowledge about and intimate violence (Ahmad et al. 2009).

This study is the first of gender relations and of DVAW within any Libyan migrant community. This study situates violence against women within a wider framework of patriarchal gender relations and gender regimes (Connell, 2009). The study finds a good deal of continuity in attitudes to DVAW; the article explores reasons for this. It also finds that some people - mainly, women - were influenced by the more liberal and law-based context in the UK in terms both of attitudes and actions.

The article is organised as follows. The concepts of gender regimes and gender orders are outlined and then discussed with reference to Libyan society. The research methodologies used in the study are described. The main findings of the study are analysed. Reasons for the relative continuity in beliefs and attitudes towards DVAW are discussed in the context of migrant situations, before some indications of changes are explored. 


\section{Gender Regime/s and Gender Orders}

Connell's concepts (Connell, 1987; 2002; 2009) of gender regimes and gender orders provide an instructive frame for discussion of attitudes to DVAW among this migrant community. This section outlines the concepts before discussing these with reference to gender regimes within Libyan society.

Connell $(1987$; 1995) notes that gender is an organisation of social practices relating particularly to human bodies and processes of reproduction. Gender differences are subject to a hierarchy of value, which leads to inequality of life-chances. Thus, gender difference mean gender inequality.

The structural inventory or gender regime (Connell, 1987) of an institution or wider society accounts for structures of gender such as labour and power that constrain or enable practices in a given context (George, 2005). Gender orders are produced through four intersecting facets of gendered lives and processes, which affect the social organisation of gender (Connell, 2002).

These are: i) Gender power relations (control, authority), ii) production relations (the cycle of production and reproduction), iii) emotional relations/ cathexis (marriage and family systems, sexuality), and iv) symbolic representations and relations (e.g. cultural and religious meanings of gender; beliefs about gender).

Connell argues (2002) that the gender order of male domination combined with hegemonic masculinity (Connell, 1995) legitimises DVAW. Although many gender orders are patriarchal, they are not immutable and can be changed and challenged, including in a direction of greater 
gender equity. The next sections will discuss how the framework might apply within Libyan communities.

\section{Gender Regimes in Libyan Arab Communities}

The diagram below is an attempt to 'map' the gender order in Libyan society onto Connell's concept of gender regime. It shows the four intersecting sets of social relations that help to organise the positioning of men and women within asymmetrical gender orders.

(Figure 1. Gender regimes supporting DVAW in Libyan families and communities)

Thus, i) gendered power relations in Libyan communities are structured by the premise of male domination in society as well as within the family. More specifically, this specifies the positioning of men as heads of families, and women as dependents: this underpins male authority and control over women. Gendered power is buttressed by the lineage or extended family and the idea of family as a strictly 'private' unit under male control. Kinship is central to Arab society (Shryock, 2000; Therborn, 2004).

ii) Production relations and the division of labour in Libyan Arab communities usually specify that women do domestic work and men work for wages outside the home, or else own farms and enterprises. Men control land, property, income and decision-making within families. Women's prime roles are as wives and mothers. Wives in Libya require the husbands' permission to work outside the home. Women migrants may, thus, not be able to access paid work even if they are educated.

iii) Emotional relations, including sexuality, or cathexis: marriage gives men the right to control wives and children and 'good' women traditionally accept their roles or risk reprisals. Female sexuality may only be expressed within marriage, and the 'honour' of families and men is 
closely-linked to control over women's sexuality. Moreover, women [let alone girls] should not contradict the father/ husband, especially in public. These aspects of personal control can extend to control through violence.

iv) Symbolic relations: socio-cultural and religious practices within Libyan communities position men as powerful and authoritative and women as inferiors and as less than adult. Additionally, aspects of sharia law are widely understood and misinterpreted in a manner which supports and maintains gender inequality and women's subordination (Mashhour, 2005; Mir-Hosseini, 2006; Moghadam 2004). Men's power is maintained by control over resources. In the public sphere, males share power. Within the private sphere of extended and nuclear families, the senior male member wields power over others, including younger men (Haj-Yahia et al., 2002).

In Libya, force and the use of power to control women are not always considered abuse: rather, such acts are often perceived as 'corrective' measures (Joseph, 1996a). Cultural aspects of male domination in Arab communities often support the concealment of DVAW, which is considered to be a family matter (Ahmad et al., 2004). Any public intervention is seen to undermine kinship relations. Families make serious efforts to maintain their reputations. Ostensibly, this concerns the reputation of female members, but it could be argued that men are the ones 'protected' by silence. Abused women may receive temporary protection, shelter, and support from their natal families if they experience violence and if relations are good (HajYahia, 2000b) but should not venture outside this context. Even where any public, voluntary or state-backed assistance is available, consulting these is seen as a matter of shame (for women) and dishonour (for men), as the studies cited earlier indicate.

The following section outlines the research methodologies used in this study. 


\section{Research Methodologies}

The research on which this article is based used a mixed-methods approach: it included both quantitative and qualitative methods. The research was carried out in 2012 and 2013 in Manchester and Leeds, over a 14-month period. The quantitative element of research entailed administration of a survey questionnaire to 175 people (108 women or $62 \%$; 67 men or $38 \%$ ). The qualitative element - semi -structured interviews - included a sample of 20 people; 13 women and 7 men. All interviews were conducted in Arabic by the lead researcher, who is Libyan.

Some, but limited, information exists concerning Libyan migrants to the UK. According to the last census, 15,046 Libyan nationals resided in the UK in 2011 (Office of National Statistics, 2012). Manchester's Libyan population is some 10,000 (Smith and Yeginsu, 2017), the largest Libyan community outside the country itself. The total number of Arab people living in the UK in 2011 was approximately 240,000 (ONS, 2012: 14) - although that figure includes British-born people also identifying as Arab. Many Manchester Libyans live

in the north of the city. Arab - UK migration was historically, mainly male (Richards and Waterbury, 1996). Most Libyans in the UK are first-generation migrants and a number are classed as temporary residents.

Brad (2008) reviewed official data on Libyan migrants to the UK, and stated that the great majority of Libyan migrants were students and businesspeople (2008: 108). However, the number of Libyans seeking asylum had increased in 2008, including a number of Libyan women. Women's reasons for seeking asylum included threats of gender-based abuses of human rights, including honour-based killings (Home Office, 2007: 8). 
The sample on which this study was based, included Libyan people who were resident in Manchester or Leeds and who held either temporary or permanent residence status. That is, no undocumented migrants who might have been particularly insecure, were interviewed. The community, as noted, was sufficiently large to ensure anonymity.

The questionnaire employed was carefully framed in light of the difficulties involved in defining and measuring DVAW and with regard to ethical criteria: for instance, women were never asked directly about their own experiences. It covered aspects such as: demographic backgrounds; definitions of violence against women; perceptions of causes of DVAW; potential justifications; views on incidence; views on differences between Britain and Libya with regard to DVAW; and views on DVAW within Libya.

Sample participants were contacted through several venues in Manchester and Leeds, using 'snowball' methodology. Venues included: a Libyan 'weekend' school (interviews with parents and teachers); a south Manchester mosque and a Libyan women's group. Many participants were approached individually, as acquaintances of friends which enabled a wider 'spread' - e.g. shopkeepers, some professionals as well as postgraduate students. An initial pilot study was carried out to ensure reliability and consistency.

Data from completed questionnaires were analysed using SPSS (version 19.0). The three main statistical techniques used for the analysis were: descriptive statistical analysis, crosstabulation matrices and regression and multi-regression analysis.

\section{Sample characteristics/description:}

Questionnaire sample: Of the 67 men and 108 women in the questionnaire sample, approximately $38 \%$ were single, $58 \%$ were married, $3 \%$ were divorced, and $(2 \%)$ were widowed. Most participants were aged under 55 years, with approximately $65 \%$ aged between 
31-50. Approximately $27 \%$ were aged between $20-30$ and $8 \%$ were over 51 . Equal percentages of the sample came from large cities in Libya (e.g. Tripoli, Benghazi, Misrata) and from small towns (e.g.Zawiya, Ajdabiya, Derna, Gharyan, Msallata), making previous residence a useful comparator.

In terms of educational levels, two people had no formal education; $2 \%$ of participants (four people) had only completed primary school, and $44 \%$ of the sample had ended education at secondary level. Of the rest, $23 \%$ of participants possessed Bachelor's degrees, approximately $22 \%$ had completed Masters degrees and approximately $8 \%$ held PhDs. Thus, $53 \%$ of this sample had high levels of education, those for men being higher than those for women. These high educational levels in part reflect that many Libyans migrate to the UK to study, but this means that the sample did not compare with educational levels in the Libyan population as a whole. ${ }^{1}$ Large percentages of the sample reported that they did not work in the UK: $59 \%$ of men and $68 \%$ of women. For men in particular, this could indicate reduced employment opportunities in the UK or reluctance to mention informal employment.

\section{Qualitative sample:}

The age of the 13 women who participated in the semi-structured interviews ranged from 3154, with the mean and median age being 41 years. All lived in Manchester. Seven women were married, five were divorced and one was single. The majority of married and divorced women had migrated to the UK soon after marriage in order to join their husbands, who were studying, working or were asylum seekers in the UK and were, in the main, permanent residents. In terms of educational background, five women held secondary school diplomas and six had a

\footnotetext{
${ }^{1}$ According to the Libyan Census Report (2006), 14.3\% of Libyan women and $15.66 \%$ of Libyan men obtained 'higher' levels of qualification i.e. ranging from post 16 to university level.
} 
Bachelor's degree. Two women had only primary school-level education. Two women had been in the UK for two years, whilst five had lived in Britain for 9-12 years and six women, for 17-24 years.

At the time the qualitative research was carried out, male participants were aged between 3349 years, with the mean and median age being 39 years. Three men had finished secondary school, two men had gained a Master's degree and one had attained a PhD. Three of the seven men were single, whilst four were married. Two men resided temporarily in the UK and five were permanent residents. Five had lived in the UK for 8 years or less; the other two men had lived in Britain between 17-33 years. Five men were middle class in Libya, whilst one man considered himself to be upper-class since he owned a business and possessed large houses in both countries. Only one man considered himself to be working-class.

The semi-structured interviews lasted, on average, 11/2 hours, with individual interviews ranging from 45 minutes to three hours. All interviews were carried out by the lead researcher, who is Libyan. The interview questions focused on thematic areas such as the concept of DVAW; attitudes towards DVAW in Libyan communities; and the influences of migration on attitudes towards DVAW.

\section{Some aspects of findings: Factors Influencing Attitudes towards Domestic Violence against Women}

The survey explored how various individual characteristics, (gender, age, education, former place of residence, marital status, length of residence in the UK, etc.), might shape attitudes to gender relations and to DVAW. Chi Square tests were carried out to discover if there were significant statistical associations between the independent and dependent variables. 
A prior expectation was that long residence in the UK might shift attitudes to DVAW within the Libyan migrant community. There is, as noted, no specific legislation against domestic or intimate violence in Libya, and widespread violence against women was tolerated under Gaddafi (HRW 2006; 2013). It was thought that residence in a society with legal instruments against DVAW - albeit poorly enforced - and which espouses norms of gender equality might influence people in the sample. Other studies of DVAW among migrants have held similar expectations. For instance, in the USA, Raj and Silverman (2005) noted that migrants may alter their views about gender relations and VAW as they live longer in the 'host' country: their ideologies might alter to accommodate relatively more egalitarian gender roles. In the present survey, however, length of stay in the UK did not correlate statistically with attitudes to DVAW.

This section outlines the factors that were found to be of statistical significance in the survey and similar patterns found from qualitative interviews, before going on to explore potential impacts of migration to the UK.

The variables 'gender' and 'educational level' were of most importance in the survey results. These were also of importance in the qualitative analysis. In addition, results from multiregression analysis showed - perhaps not surprisingly- that 'gender' was the most important factor in predicting attitudes towards DVAW.

This survey indicated important differences between the attitudes of men and women across most, although not all, measures. Gender was the most consistent factor indicating whether more "violence-supportive" views were held; this was also the case in semi-structured interviews. 
Before exploring the impact of gender on responses in this study, we note that such differences are relative. That is, a number of women as well as men justified violence in certain situations. The clearest support for physical violence against women was in the case of infringement of sexual norms. In the quantitative survey, $79 \%$ of men and $76 \%$ of women agreed that physical violence by men towards women was justified if the woman were to be sexually unfaithful. In the semi-structured interviews, eight of 13 women agreed that in such a situation, the woman (especially if married) deserved to be beaten. Although there were male/ female differences in response and justification to various questions, in many cases large percentages of women justified violence. In one example, to a survey question about whether a woman who disobeyed her husband deserved to be beaten, $58 \%$ of women agreed, vs. $67 \%$ of men: this is still a very large percentage of women. Some women also justified emotional abuse of wives/ daughters. For instance, 'Huda' (married, aged in 30s) said: "Sometimes women themselves cause violence. If the husband was angry, she should not argue with him or raise her voice...."

Despite these caveats, men in the sample were more likely to have narrow definitions of violence (e.g. as including direct physical violence only) and to justify physical and emotional violence in a range of circumstances. Women in the survey sample viewed a wider range of behaviours as constituting 'gender violence'. For instance, women were much more likely than men, to agree that 'persistent verbal abuse, denying women access to money; forbidding the wife to leave the house, slapping or punching her, and forced marriage were all aspects of DVAW. Or, in another indication, only $33 \%$ of men but $65 \%$ of women agreed that women's dependence on men for food, shelter and income meant that women were more likely to suffer abuse and violence $(\mathrm{p}<0.022)$. Asked whether toleration of violence against women led to it recurring, women were more than 6 times more likely than men to agree (Odds Ratio $=6.07$ ). 
Gender differences in attitudes toward violence have also been widely documented in other studies (e.g. Antai et al., 2008; Haj-Yahia, 2002, 2003; 2005; Rani and Bonu, 2009). These studies confirmed that men are more likely than women to agree with myths and beliefs that are supportive of DVAW. The studies further state that men are more likely to victim-blame, to minimise harms associated with physical and sexual assault, or not to understand behaviours constituting DVAW to be damaging to women (see also Dobash and Dobash, 1998).

Consistent with other research, men in this study were more likely than women to endorse beliefs minimising rape and spousal violence and statements that tended to 'blame the victim'. DVAW was justified by men more than women in several circumstances. For example, the quantitative analysis revealed that approximately $71 \%$ of men agreed that a husband could justifiably beat his wife if she neglected her children, versus $56 \%$ of women who agreed. Men agreed far more than women, that a wife who disobeyed the husband's parents deserved to be beaten $(\mathrm{p}<0.016$; Odds Ratio $=2.56)$.

The main differences between men's and women's attitudes were in terms of 'using physical violence as a strategy to control women'. Some men in the survey stated that using physical violence was perhaps an acceptable way to deal with women, but none of the women in the survey agreed that women deserved violence in 'everyday life'. In day-to-day situations (such as: if a woman went out without telling the man in the family, argued with him, disobeyed him, didn't do domestic work to the required or hoped for-standard) none of the women considered physical violence to be acceptable.

The qualitative analysis indicated that men interviewed showed a tendency to justify verbal and emotional abuse more than did women. In the semi-structured interviews, the seven men interviewed initially stated that DVAW was wholly unacceptable. However, later in the 
interviews, all but one informant qualified his statements and some contradicted themselves. Five of seven men justified emotional and verbal abuse and indicated that they thought this was normal within marriage. Hamdi (30s, single), for instance, felt that verbal abuse 'would not harm' the woman and that the man has a right to feel that he owns the home. Ahmed (40s, married), said:

"Women should be careful; they have to follow the social rules. For instance, she does not need to go out without her husband's permission. Women should follow and respect social norms. Why [does] she raise the man's anger?"

Four of the seven also justified physical violence in a number of situations: e.g. not dressing modestly (particularly, wearing of hijab); arguing with the husband; leaving the house without permission; causing the husband to feel he does not have complete control; bringing shame upon the household. As one example, Samir (30s, single) stated,

"Some women need to be beaten by men - when a woman only wants to talk and to spend money the man has to be strong to make her as he wants. Otherwise, he will lose control in his own place."

Thus, although there were tendencies to justify DVAW among both women and men in the sample, this was much more marked among men interviewed.

Education should provide women with more resources to escape from control and is therefore likely to empower them through obtaining better employment, hence, gaining financial independence. In a study of Jordanian university students (Araji and Carlson, 2001), fathers' occupational status and a mothers' education significantly influenced students' attitudes towards DVAW. Students whose mothers were well-educated perceived DVAW to be a very serious problem. The results from the present survey - which had disproportionate numbers of 
highly-educated people - indicated that educational level was linked with a number of statements. These included: 'Tolerance of violence leads to more violence'; 'The inherent inequality between male and female in society leads to violence' and 'Boys who witness their father's violence towards their mothers are more likely to be violent'. In the survey, women with high educational levels were more likely to define DVAW broadly. In the semi-structured interviews, women with degree-level qualifications spoke more about DVAW and in greater depth about all types of violence. This suggests that the more educated that women become, the more likely they will have an increased awareness of DVAW.

A study in rural Bangladesh (Marium, 2014) concluded higher education levels were important in protecting women from DVAW. However, our study contradicted these findings, suggesting that education may not change views or protect women from violence. Several women in the semi-structured interview sample who were more educated and empowered also faced a greater risk of violence as their husbands tried to regain control by controlling their salaries. Therefore, in this study, women's high educational levels did not limit their exposure to violence in practice. In this instance, educational level was only important in relation to the building and shaping of the participants attitudes, as men remained dominant within marriages. Ackerson et al. (2008) and $\mathrm{Xu}$ et al. (2005) found (respectively) for India and China that women with a higher level of education compared to that of their partner were more likely to experience physical violence. These studies support the experiences reported by some women from the semi-structured interviews in this research.

The variables 'age' and 'former place of residence in Libya' were also of significance, although more sporadically. For instance, respondents aged under 40 were more likely to agree to a broader definition of DVAW. There was also a significant relationship between age and the statement 'Women in Libya should fight for their rights', with women under 40 
years much more likely to agree $(\mathrm{p}<0.017)$. Participants under 40 were also much more likely to say that laws in Libya were inadequate to safeguard women against DVAW.

Former place of residence in Libya was linked to several variables. In terms of definitions of violence, participants who came from large cities were more likely to agree that 'DVAW includes depriving women of money and clothing ` $(p<0.022)$. They were also more likely to agree with the statement: 'women who earn more than men are more likely to become victims of domestic violence` than were participants from rural areas/ small towns. Respondents from urban areas were much more likely to agree (Odds Ratio $=5.4)$ that 'toleration of violence leads to its recurrence'. Former place of residence in Libya was also linked statistically to the statement 'Women should be encouraged to speak out about violence against them', with participants from large cities far more likely to agree $(\mathrm{p}<0.014)$. Asked whether changes to the law in Libya with regard to DVAW was needed, participants who had lived in large cities prior to migration were 3.8 times more likely than those from small towns or villages to state that legal change was needed. These findings indicate that there was a difference between attitudes to DVAW between urban and rural people, with urban people holding less violencesupportive attitudes. This is in line with many if not most, societies where rural and agriculturally-based people tend to hold more conservative attitudes concerning women's 'place' and possibilities for autonomy (e.g. Jacobs 2001; Istenic, 2007; Yount, 2009; Bock and Shortall, 2017).

\section{Impact of Migration}

A striking finding in this research, as noted, was that length of stay in the UK did not correlate statistically with attitudes to DVAW. In other words, migrants' frameworks were less 'cross- 
national' and more rooted in the Libyan context than anticipated. Al-Habib (2011) also found in her thesis on Saudi migrants to the UK that length of stay did not relate to attitudinal change.

In both samples in this study, many respondents had lived in Britain for a number of years. In the questionnaire sample, just over $40 \%$ of respondents had resided in the UK for 11 years or longer, while $60 \%$ (62.7\% of men; $57.6 \%$ of women) had lived in the UK for 10 years or less. In the qualitative sample, the mean number of years of residence was 14 . This section explores social, cultural, economic and legal factors that might help to explain (relative) continuity of attitudes and beliefs.

In order to contextualise this, we first outline some research concerning DVAW among migrants. Although specific cultural contexts are important - as outlined in the earlier discussion of gender regimes - so too are migrant situations more generally. Relatively few studies exist, and few concern Arabic-speaking women. Geographically, more studies of VAW and migration have been conducted in the USA than elsewhere.

Studies indicate, as noted earlier, that the factors of language barriers; isolation, insecurity due to legal status, economic changes induced through migration, and community pressures (and cohesion) and 'dual' frames of references are common for women throughout many migrant communities, whatever their origins, religions and cultures (e.g. Menjívar and Salcido, 2002; Raj and Silverman, 2002)

Research indicates that the problem of 'naming' violence persists within many migrant communities. For instance, Sidiqi (2008) in a study Pakistani migrants to the UK noted that most immigrant women did not recognise sexual assault by an intimate partner as 'violence'.

Migration presents people with new settings, circumstances and (sometimes) new cultural milieux to which they must respond or adjust (Akpinar, 2003). Many - both men and women 
- often face discrimination on the basis of ethnicity, 'race', religion and /or legal status; this often intersects with gender discrimination. As a response, some communities may turn inwards, partly as a means of protection. This means that existing gender norms including male domination, can be seen as a cultural 'good' to preserve (Bhuyan et al. 2005). Relatedly, women are often symbolised as keepers of ethnic/religious and racialised boundaries (Anthias and Yuval-Davis, 1992).

In US studies, findings from Middle Eastern and (various) Asian communities indicated that both men and women often believe that if women do not remain within assigned roles in the home and community, it is acceptable for men to 'discipline' them, including physically (Huisman, 1996). Thus, patriarchal gender beliefs and actions may not disappear but persist, despite new contexts or a new type of 'patriarchal bargain' (Kandiyoti, 1998).

Existing or 'traditional' norms may persist within migrant contexts. USA studies have found that gender roles in migrant communities can justify abuse and enforcement of female subservience - or even increase this- through wives' and daughters' isolation and dependent status (Bui and Morash, 1999; George and Rahangdale, 1996). Migration can increase isolation for women in a number of ways, and this is a theme common in research on gender and migration (e.g. Raj and Silverman, 2002; Menjívar and Salcido, 2005). Women are often isolated from their own (natal) families and therefore become more dependent on the husband, or sometimes, the husband's parents or extended family. Lack of knowledge of a new language and context may increase isolation and insecurity. So, too, may the lack of access to employment that women often experience, whether unemployment is due to familial/ cultural norms or wider discrimination in the labour market. In this volume, Duda-Mukulin (2018) found that lack of job security contributed to precarity experienced by Polish women migrants. 
Ideas of honour and shame (see above) can also continue to play an important role in reinforcing unequal gender regimes. Women can bring 'shame' upon families and men (and themselves) through their dress (e.g. failure to wear hijab; wearing immodest clothing); through their sexuality, through public disagreement or simply through displays of independence. In Libyan and a number of other societies, women's instigation of divorce (or even divorce by the husband) is also seen as shaming for the woman. The matrix of honour and shame remains strong in many communities and women as well as men may adhere to these beliefs. For instance, Ahmad et al. (2004) found for south Asian migrants to the USA, that ingrained values relating to honour and shame could be found even among second and third-generation migrants. Abu Ras $(2003 ; 2007)$ found 'traditional' attitudes relating to DVAW among Arab-American women in Michigan, so that women like men, adhered to beliefs in women's propensity to shame men and wider families. Abu Ras found additionally, that of the 86 women migrants interviewed, all had been subject to at least one violent incident at home. Women only very rarely tried to access services.

Many women greatly fear divorce. This is in part due to its 'shameful' nature, but also because of financial and economic implications in situations where most women lack access to jobs. Divorce can also mean potential loss of custody of children. All of these factors may mean that women adhere to traditional roles and values - or in any case, feel that they must be seen to do so.

A number of studies report a powerful impetus for women to keep discussions/ reports of DVAW within the family and/or community -- as is the case within Libyan communities. This too is linked with honour and shame, as discussions of DVAW, especially outside the family, are often seen as shaming for all parties. Bhuyan and Senturia (2005) found in USA participatory research involving nine different (and global) national/ ethnic communities, that 
women in all communities were subject to pressure to avoid seeking remedies from the state or from outsiders. They comment, additionally, that despite denouncing DVAW publicly, all communities in the study were complicit through trying to block women's access to assistance and to any resources available. Thus, although this pressure is relevant for Libyan woman migrants, it operates very widely across cultural contexts - including dominant cultures within 'host' countries themselves.

Where men are un or under-employed or unable to fulfil traditional obligations as breadwinners, this may cause shaming disruptions of traditional masculine identities. In turn, male outbursts against female family members may increase (Erman, 2001). Relatedly, a number of women migrants do seek more independence - e.g. through education; employment; friendships. Baker et al. (1999) found for Latino migrants to the USA that such actions could also put men in a shameful position and could increase violence. (see also: Menjívar and Salcido, 2002; Raj and Silverman 2002).

Castells notes (2010) that when women's education increases, when some women gain employment and when legal discrimination decreases, interpersonal violence and psychological abuse are widespread - precisely because of male anger, individual and collective, at losing power. He continues, "this is not, and will not be, a velvet revolution" (2010:194). Efforts to become more autonomous or simply to assert more equal gender norms may, then, be risky.

Thus, migrant 'conditions' - especially for women - may be ones of insecurity, instability, relative isolation and fracturing of identity. 
We now (re)turn to discussion of findings from this sample of Libyan migrants. As noted, gender orders and regimes may not have altered substantially in the context of sometimeslongstanding migration. It should be noted that the violence-supportive context in Libya itself is likely to be of relevance. Libya at the time of fieldwork was in a fragile, post-conflict situation and remains so. Male authority persists within the state and the military. Under Gaddafi, DVAW was not criminalised (Fhelboom, 2014) and the few interventions that took place late on in the regime sometimes further victimised women (HRW, 2013). DVAW still remains a largely-taboo subject. Shaban (2013) found that post-Gadaffi, Libya is highly militarised, male dominant and a place of danger for many women.

Participants were likely to be aware of this context, which would do little to lessen feelings of insecurity. Not all in the sample had a Right to Remain in the UK, and therefore faced insecurity in terms of migrant status in case they wished to settle. Moreover, migrants often have networks of Libyan friends and acquaintances and retain strong ties to Libya. A number of women respondents mentioned the lack of legal protection for abused women within Libya and were sceptical about the possibility of enforcement, even if there were to be legislation protective of women's rights. These factors may help to reinforce existing gender regimes. A few indications from the present research are given below.

Many men in the sample held the view that men should be 'respected' by women - who should in turn obey male requests and instructions. Within the semi-structured interviews, and in the survey, as noted, a number of women as well as men justified DVAW in certain circumstances.

As noted, this research did not enquire directly about women's experiences of violence, but some responses indicate that the levels may be high. Emotional and verbal violence was mentioned by 9 (of 13) women in the semi-structured interviews, and all but one woman said 
that they 'knew of a woman' who had been subject to physical violence. It is difficult to know whether women were referring to themselves or perhaps to family or close friends.

Control over women's persons intertwined with economic control. In this sample, wives had relative little influence over important household decisions despite the fact that in the UK, most lived in nuclear families. They did, however, usually have influence and say over more minor, everyday decisions. Most women (68\%) did not work outside the home (see also DudaMukulin (2018) in this volume on expectations of attachment to the household.). Another 17\% of the female sample worked for pay, but in Libyan (weekend) schools which were gendersegregated and which paid little. ${ }^{2}$ Men held power through control over income (including, wives' incomes where applicable) and property and over wives' movements. Some women needed the husband's permission for a whole range of actions. Some women who had been abused cited economic and financial dependence as an important precipitating factor; dependence also meant that they could not leave their abusers. The importance of marriage and family and associated ideas of honour and shame meant that several women in the sample felt that remaining in a violent relationship was preferable to being divorced.

Thus, a number of factors converge so that changes in attitudes to DVAW in this sample were limited.

\section{Some Changes}

Changes in attitudes and behaviour among the sample were, nevertheless, evident in some instances. This section outlines and discusses several indications of change.

Asked whether British culture differed from that in Libya with regard to DVAW, $70 \%$ of men and $62 \%$ of women overall and $80 \%$ of highly-educated women, agreed that there exist differences. Within the semi-structured interviews, all participants agreed that life in the UK differed from that in Libya with regard to attitudes to DVAW. It was felt that women in Britain 
had more rights, that there was a stronger legal framework; that DVAW was a matter for public debate and it was believed that the state and social work departments would attempt to protect women from violence. People in both samples were asked whether life in the UK had impacted on how men dealt with women and how they perceived DVAW. In the survey, a majority thought that living in the UK had changed male attitudes and behaviour: $52 \%$ of men and $61 \%$ of women (and $67 \%$ of less-educated women) - although this means that $48 \%$ of men felt there had been no change. In the semi-structured interviews, 4 of the 7 men interviewed said that life in the UK had not altered their attitudes or views, whereas 11 of the 13 women interviewed said that migrating to the UK had changed men's (and their own) behaviour and attitudes. Of the two women who responded negatively, one had lived in Britain for less than two years. Of the four men responding negatively, three had lived in the UK for five or fewer years. Thus, the semi-structured interviews and to a lesser extent, the survey, indicate that migration had influenced views about DVAW, especially among women.

In the survey questionnaire, people were asked a range of questions about the law and about assistance outside the family available for women within Libya itself. The latter is a contentious but much-discussed issue. Although this was not a direct indication of change, there was a statistically significant relationship between gender and a question enquiring whether abused women should consult a lawyer, with women much more likely than men to agree with such a course of action $(\mathrm{p}<0.04)$.

${ }^{2}$ Of the remainder of women sampled who were employed, $7.4 \%$ were in professional or managerial jobs (including working as doctors); 6,8\% in food and transport sectors and the rest were in 'other' sectors.

In the semi-structured interviews, people were asked more directly whether it was acceptable or desirable for women to seek help from outside the family in cases of DVAW. Some men, particularly among respondents with less education, remained vehemently opposed to women 
seeking assistance from formal agencies. 'Akram' (mid-30s, single), for instance, considered that this would infringe traditional mores. He said,

"Women should not contact the police when they are in a violent relationship. Libyan women cannot contact police: women should speak to their father or brother to help them... It is stigma and scandal for women to go to the police and it means the end of the marriage. Libyan women in the UK... change their values, they become like the English. They forget their own family!" Women in the qualitative sample, however, were much more likely than men to think that DVAW was a matter for public authorities. Several of the women said that they had sought 'outside' help or would advise other women to do so - e.g. from a GP, a social work department or a lawyer. Additionally, this sample included five divorced women, a relatively high proportion - perhaps because divorced women did not require permission to conduct an interview. Of these, all had suffered violence within their marriages, usually over years. Two cases are instructive. In one, a highly devout woman in her 40s, 'Mayada', stated that living in the UK had not changed her strict views. She spoke no English and did not wish her children to integrate into wider society. However, in practice Mayada went to the GP for support when suffering from depression and isolation. She also contacted the local Council and the GP, using interpreters, for assistance for a disabled child. Thus, she had been highly proactive when seeking assistance for her family and for herself. At the other end of the class 'scale', a professional woman in her 50s had suffered violence for many years. Although she said she would not have contacted police in Libya, she did so in the UK:

“...because I am here [in the UK] I went to the police when my ex-husband beat me, and requested divorce. I got divorced in the UK. Staying here ... helped me a lot, I had the strength to stop the violence I had faced for more than 16 years..." ('Aisha') 
Thus, a number of women did use services and sought help - or expressed the view that this was a desirable course of action. This was despite widespread disapproval within the community.

\section{Conclusion}

This study has indicated marked continuity in existing gender regimes and in views about DVAW within this sample of migrants. The household as a 'micro-level' of control continues to be influenced by norms from the more patrilineally-based extended families in Libya. Husbands in the sample usually expected to exert authority and control over wives, including over women's incomes, dress and activities. Traditional gender regimes in Libya also, as discussed, entail tacit toleration - if not wholesale acceptance - of some forms of gender violence, particularly where issues of honour and shame are involved.

The majority of Libyan migrants in the north of England live in nuclear families. These may offer an increase in freedom but also mean that women remain without support from their own relatives. However, migrants usually establish close networks of mutual (emotional, practical) support with other country people, including living near one another and this is the case for many Libyan migrants. Read (2003) also found that US Arab migrants living in close-knit communities tended to reproduce traditional gender norms. Communities lend a sense of belonging in a new and potentially confusing or alienating. Thus, social and gendered norms may be maintained as a way of expressing belonging and identity. Communities can be a source of friendship, links with the homeland and mutual assistance but can also be sources of social control. 
Additionally, as other studies indicate (see above), many migrant women suffer from isolation. This may be the case especially when their language skills are poor and where husbands control wider contacts. Few women in this sample worked for wages, and many of those who did worked in Libyan weekend schools. Even without family constraints, women may struggle to find employment after migration, given discrimination in the labour market. Those without a legally settled status (i.e. the Right to Remain) in the UK would be likely to feel insecure: this is a very concrete source of precarity. Migrants who are not 'settled' might have particular reasons to maintain strong links with Libya.

Women, like men, may of course choose to endorse traditional gender regimes and arrangements, especially if these are seen as religiously-sanctioned. Those who differ, or who simply seek greater autonomy, may face constraints. The wish and need to maintain links with the homeland and kin; economic insecurity and migrant precarity combine so that most women have little option but to conform to traditional expectations.

A number of fractures in identity and in existing beliefs and practices are also evident from this research. The great majority of respondents, when asked directly about physical violence towards women, distanced themselves from endorsement - although as discussed, a large minority of men in interviews later contradicted themselves or suggested circumstances in which DVAW was justified. Women in this sample held much less violence-supportive and violence-minimising views than did men. And, at least some women displayed great independence in their own actions.

For instance, several divorced women brought up children themselves; a number of women sought advice from 'outside' agencies despite perceived shame in taking issues outside the family. A number of women do use services available, including sometimes reporting violence 
to police. It is perhaps relevant that women with more secure migrant status were more likely to report violence; to seek divorce and to risk heading a household. And large numbers of women felt that women should 'speak out' and should use legal frameworks to counter domestic and intimate violence and to assert themselves.

This study indicates that patriarchal gender regimes among Libyan migrants in the north of England do show much stability. However, this story is one of contestation as well as of continuity.

\section{Tables}

Figure 1. :Gender regimes supporting DVAW in Libyan families and communities

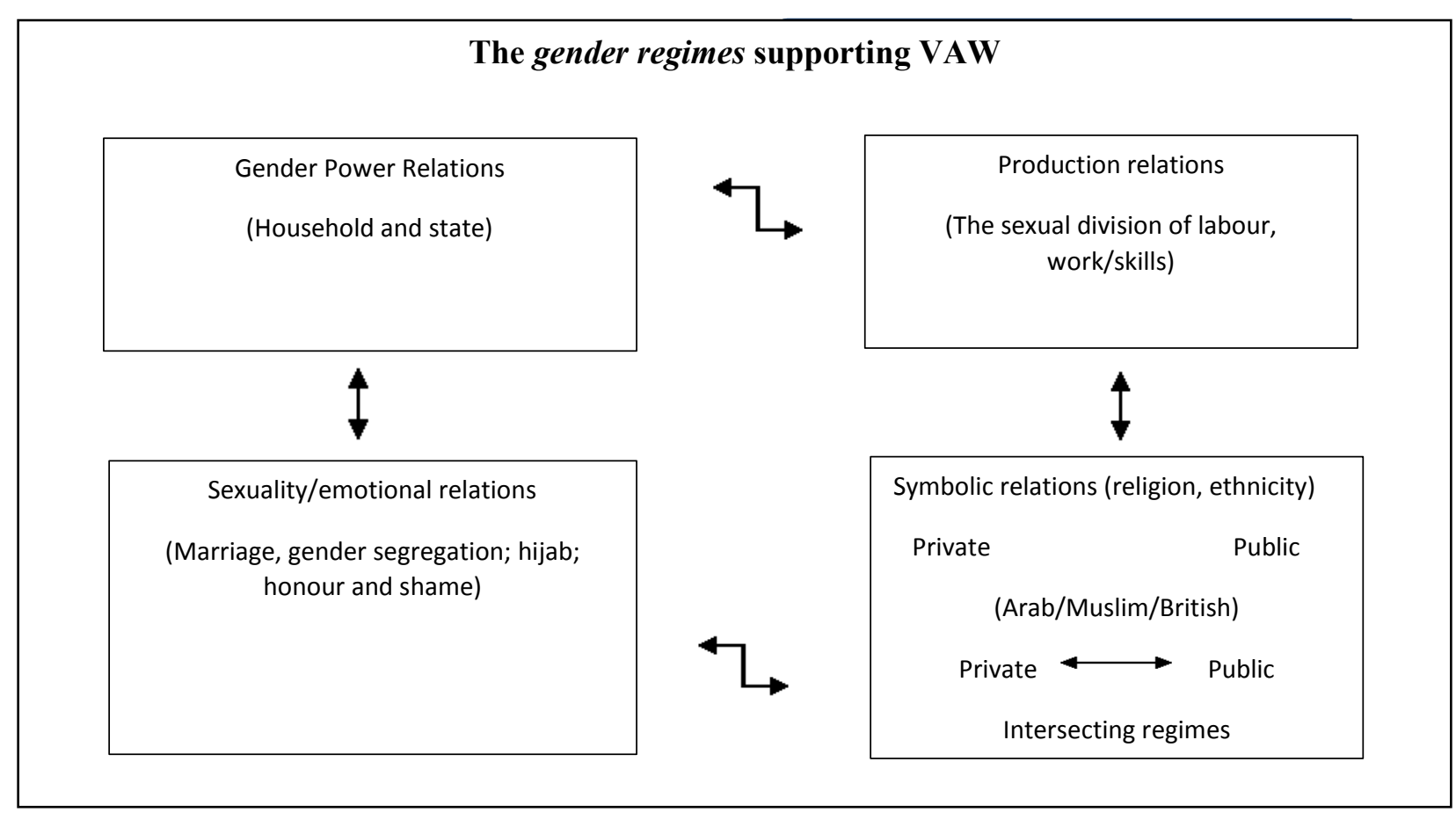




\section{References}

Abdul-Latif, A. (2013) 'Libya Status of Women Survey: A Nationwide Survey examining the Civic, Political and Economic Participation of Libyan Women and exploring Public Attitudes towards Women's Roles, Rights and Domestic Violence. Available at: http://www.wluml.org/sites/wluml.org/files/Libya $\% 20$ Status $\% 20$ of $\% 20$ Women $\% 20$ Survey \%20Report final2.pdf [Downloaded October, 2014]

Abu-Ras, W. (2003) 'Barriers to Services for Battered Arab Immigrant Women in a Detroit Suburb'. Social Work Research and Evaluation, 3(4): 49-66.

Abu-Ras, W. (2007) 'Cultural Beliefs and Service Utilization by Battered Arab Immigrant Women`. Violence Against Women, Vol.13: 1002-28.

Ackerson, L.K., Kawachi, I., Barbeau, E. M. and Subramanian, S.V. (2008) 'Effects of Individual and Proximate Educational Context on Intimate Partner Violence: A populationbased Study of Women in India'. American Journal of Public Health, 98(3):507-514.

Ahmad, F., Riaz, S., Barata, P. and Stewart, D. (2004) 'Patriarchal Beliefs and Perceptions of Abuse among South Asian Immigrant Women'. Violence Against Women, 10(3): 262-282.

Ahmad, F., Driver, N., McNally, M. J., \& Stewart, D. E. (2009). "Why doesn't she seek help for partner abuse?" An exploratory study with South Asian immigrant women. Social Science \& Medicine, 69(4), 613-622

Ahmed, M. and Naseem, F. (2011) 'Social System Influences Political System a Comparative Study of Sub-continent'. Berkeley Journal of Social Sciences, 1(1):1-11.

Akpinar, A. (2003) 'The Honour/Shame Complex Revisited: Violence against Women in the Migration Context'. Women's Studies International Forum, 26(5): 425 - 442.

Al-Habib, S. (2011) The prevalence and experiences of intimate partner violence among Saudi women in the UK. Doctoral Thesis. University of Bristol.

Alkkly, B. (2005) Domestic Violence Causes and Effects. Tripoli: Research Centre for Libyan Women's Studies (in Arabic).

Allteer, M. (1997) Domestic Violence. Riyadh: Naif Arab Academy for Security Sciences Studies and Research Centre (in Arabic). 
Almosaed, N. (2004) 'Violence against Women: A Cross-cultural Perspective'. Journal of Muslim Affairs, 24(1): 67-88.

Anthias, Floya and Nira Yuval-Davis (1992) Racialised Boundaries: London: Routledge.

Araji, S. and Carlson, J. (2001) 'Family Violence Including Crimes of Honour in Jordan Correlates and Perceptions of Seriousness`. Violence against Women, 7(5): 586-621.

Awaz, D. (2010) Domestic Violence against Women and Children. Tripoli: Research Centre for Libyan Women's Studies (in Arabic)

Baker, N.V., Gregware, P.R. and Cassidy, M. A. (1999) 'Family Killing Fields. Honour Rationales in the Murder of Women`. Violence Against Women, 5(2): 164- 184.

Bharani, H. (2013) 'Domestic Violence and Human Rights'. International Research Journal of Social Sciences, 2(9), 7-10.

Bhuyan, R. and Senturia, K. (2005) "Understanding Domestic Violence Resource Utilization and Survivor Solutions among Immigrant and Refugee Women: Introduction to the Special Issue" J. Interpersonal Violence 20(8): 895-901.

Bhuyan, R., Mell, M., Senturia, K., Su, M. and Shiu-Thornton, S. (2005)'“Women must endure according to their Karma" Cambodian Immigrant Women talk about Domestic Violence' J. Interpersonal Violence 20(8): 901-21.

Bock, B. and Shortall, S. (eds) (2017) Gender and Rural Globalization: International Perspectives on Gender and Rural Development . Oxford: CABI International.

Brad. K B. (2008) 'Libyan Nationals in the United Kingdom: Geopolitical Considerations and Trends in Asylum and Return'. J. of Multicultural Societies 10(2): 106-127.

Bui, H.N. and Morash, M. (1999) 'Domestic Violence in the Vietnamese Immigrant Community: An Exploratory Study'. Violence against Women, Vol. 5: 769-795.

Castells, M (2010) The Power of Identity: The Information Age: Economy, Society, and Culture. Wiley-Blackwell.

Connell, R.W. (1987) Gender and Power: Society, the Person, and Sexual Politics. Stanford: Stanford University Press.

Connell, R.W. (1995) Masculinities. Berkeley: University of California Press. 
Connell, R.W. (2002) Gender. Cambridge, Polity Press.

Connell, Raewyn (2009) Gender: Cambridge: Polity Press.

Crenshaw, K. (1991) Mapping the Margins: Intersectionality, Identity Politics, and Violence against Women of Color. Stanford Law Review. 43(6): 1241-1299

Dobash, R.E. and Dobash, R.P. (1998) Rethinking Violence against Women. Sage Publications.

Douki, S. Nacef, F. Belhadj, A., Bouasker, A. and Ghachem, R. (2003) 'Violence Against Women in Arab and Islamic Countries'.Archives of Women Mental Health. 6(3): 165-171.

El-Zanaty, F. and Way, A. (2006) Egypt Demographic and Health Survey 2005. Cairo, Egypt: Ministry of Health and Population, National Population Council, El-Zanaty and Associates, and ORC Macro.

Fhelboom, R. (2014) 'Gender Equality Unspeakable phenomenon` D+C Development and Cooperation website. http://www.dandc.eu/en/article/libya-domestic-violence-not-talkedabout [Downloaded November 2014].

Erman, T. (2001) 'Rural Migrants and Patriarchy in Turkish Cities'. International Journal of Urban and Regional Research. 25(1): 118-133.

George, S.M. (2005) When Women Come First: Gender and Class in Transnational Migration. Berkeley and Los Angeles: University of California Press.

George, S.M. and Rahangdale, L. (1999) "Domestic violence and South Asian women". North Carolina Medical Journal, Vol. 60:157-159.

Haj-Yahia, M.M. (1998) 'Wife-Abuse and its Psychological Consequences as Revealed by the First Palestinian National Survey on Violence against Women'. Journal of Family Psychology, 13(4): 642-662.

Haj-Yahia, M.M. (2000a) 'Implications of Wife-abuse and Battering for Self-Esteem: Depression and Anxiety as Revealed by the Second Palestinian National Survey on Violence against Women'. Journal of Family, 1(4): 435-463.

Haj -Yahia, M.M. (2000b) 'Wife-abuse and Battering in the Sociocultural Context of Arab Society’. Family Process, 39(2): 237-255. 
Haj-Yahia, M.M. (2002) `Attitudes of Arab Women towards Different Patterns of Coping with Wife Abuse'. Journal of Interpersonal Violence, 17(7): 721-745.

Haj-Yahia, M.M. (2003) 'Beliefs of Jordanian Women about Wife-Beating' Psychology of Women Quarterly, 26(4): 282-291.

Haj-Yahia, M.M. (2005) 'Can People's Patriarchal Ideology Predict their Beliefs about Wife Abuse? The Case of Jordanian Men'. Journal of Community Psychology, 33(5): 545-567.

Hibbins, R. (2005). Migration and gender identity among Chinese skilled male migrants to Australia. Geoforum, 36(2), 167-180.

Home Office of the United Kingdom (2007) 'Operational Guidance Note - Libya.' Home Office Border and Immigration Agency. [online]: Available at:

http://www.ind.homeoffice.gov.uk/documents/countryspecificasylumpolicyogns/libyaogn?yi ew (Downloaded June, 2014.)

Hondagneu-Sotelo, P., (1992). Overcoming patriarchal constraints: The reconstruction of gender relations among Mexican immigrant women and men. Gender and Society 6, 393-415.

Huisman, K.A. (1996) 'Wife Battering in Asian-American Communities' Violence against Women, 2(3): 260-83.

Hunnicutt, G. (2009) Varieties of Patriarchy and Violence Against Women: Resurrecting "Patriarchy" as a Theoretical Tool. In: Violence Against Women, 15(5): 553-573

HRW [Human Rights Watch] (2006) 'Libya Country Summary Human Rights Watch', January. [Online] Available at: http://hrw.org/wr2k6/pdf/libya.pdf [Downloaded July 2013].

HRW (2013) 'A Revolution for All: Women's Rights in the New Libya', Human Rights Watch.

Istenic, M. C. (2007) "Attitudes Towards Gender Roles and Gender Role Behaviour Among Urban, Rural, and Farm Populations in Slovenia'. Journal of Comparative Family Studies; 38(3): 477-

Jacobs, S. (2001) 'A Share of the Earth?: Gender, Land and Women's Organizations in southern Africa' in M. Rees and J. Smart (eds) Plural Globalities in Multiple Localities; New World Borders, Lanham, MD: University Press of America:/Society for Economic Anthropology: 75-104. 
Joseph, S. (1996a) Gender and Citizenship in Middle Eastern States Middle East Reports. Syracuse University Press.

Joseph, S. (1996b) 'Patriarchy and Development in the Arab World'. Gender and Development. 4(2):14-19.

Kandiyoti, D. (1998) "Gender, Power and Contestation: Rethinking 'Bargaining with Patriarchy" in C. Jackson and R. Pearson (eds) Feminist Visions of Development, London: Routledge: 135-52.

Kaufman, M. (Ed.). (1987). Beyond patriarchy: Essays by men on pleasure, power, and change. Toronto/New York: Oxford University Press.

Khawaja, M., Linos, Nand El-Roueiheb, Z. (2008) 'Attitudes of Men and Women Towards Wife Beating: Findings from Palestinian Refugee Camps in Jordan`. Journal of Family Violence, 23(3): 211-218.

Libyan Census Report (2006). Libya: General Information Authority of the Government of Libya: Tripoli.

Madhabika B.N., A.G.Abraham C. A. Byrne and Mutsumi K. M. (2003) `Attitudes Toward Violence Against Women: A Cross-Nation Study`Sex Roles, 49(7/8): 333-342.

Marium, S. (2014) 'Women's Level of Education and Its Effect on Domestic Violence in Rural Bangladesh’. Journal Of Humanities And Social Science, 19(5): 40-45

Mashhour, A (2005) Islamic Law and Gender Equality: Could There be a Common Ground?: A Study of Divorce and Polygamy in Sharia Law and Contemporary Legislation in Tunisia and Egypt. Human Rights Quarterly. 27(2): 562-596

Menjívar, C. and Salcido. O. (2002) "Immigrant Women and Domestic Violence: Common Experiences in Different Countries" Gender and Society 16(6): 898-920.

Mir-Hosseini, Z. (2006) Muslim Women's Quest for Equality: Between Islamic Law and Feminism. Critical Inquiry 32(4): 629-645.

Moghadam, V.M. (2004) 'Towards Gender Equality in the Arab and Middle East Region: Islam, Culture, and Feminist Activism`. United Nations Development Programme .Human Development Report Office.

Morash, M., Bui, M. and Santiago, A. (2000) 'Gender Specific Ideology of domestic Violence in Mexican Origin Families`. International Review of Victimology, Vol. 1: 67-91. 
Office for National Statistics of the UK [ONS] (2012) 'Ethnicity and National Identity in England and Wales '2011' National Archives, Kew. [online at:

http://www.ons.gov.uk/ons/dcp171776 290558.pdf.] Downloaded, December, 2012.

Piper, N., Rosewarne, S., \& Withers, M. (2017). Migrant Precarity in Asia:'Networks of Labour Activism'for a Rights-based Governance of Migration. Development and Change, 48(5), 1089-1110.

Premji, S., \& Shakya, Y. (2017). Pathways between under/unemployment and health among racialized immigrant women in Toronto. Ethnicity \& Health, 22(1), 17-35

Raj, A. and Silverman, J. (2002) 'Violence against Immigrant Women: The Roles of Culture, Context and Legal Immigrant Status on Intimate Partner Violence'. Violence against Women, 8(3): 367-398.

Rani, M. and Bonu, S. (2009) `Attitudes toward Wife Beating: A cross-Country Study in Asia'. Journal of Interpersonal Violence, 24(8): 1371-1397.

Read, J.G. (2003) 'The Sources of Gender Role Attitudes among Christian and Muslim Arab-American Women`. Sociology of Religion, 64(2): 207-22.

Richards, A. and Waterbury, J. (1996) The Political Economy of the Middle East. Boulder: Westview.

Sadiqi, F. (2008) 'Facing Challenges and Pioneering Feminist and Gender Studies: Women in Post-colonial and Today's Maghreb '. African and Asian Studies, 7: 447-470.

Scott, S. \& McManus, S. (2016) 'Hidden Hurt, violence, abuse and disadvantage in the lives of women'. Agenda. https://weareagenda.org/wp-content/uploads/2015/11/Hidden-Hurt-fullreport1.pdf (Downloaded 5/12/2017).

Shaban, K. (2013) 'The Militarisation of Libyan Society Post-conflict: a Study of the Impacts of Increased Militarisation on the Lives of Women'. Master's Thesis, Manchester Metropolitan University, unpublished.

Shryock, A. (2000) 'Family Resemblances: Kinship and Community in Arab Detroit.' In N. Abraham and A. Shryock (eds.) Arab Detroit: From Margin to Mainstream. Detroit: Wayne State University Press.

Smith, R. and Yeginsu, C. (2017) 'For Manchester, as for its Libyans, a Test of Faith' NY Times 25 May. Available at: https://www.nytimes.com/2017/05/25/world/europe/manchester-uk-libyans.html 
Sokoloff, N. J., \& Dupont, I. (2005). Domestic violence at the intersections of race, class, and gender: Challenges and contributions to understanding violence against marginalized women in diverse communities. Violence Against Women, 11(1), 38-64.

Standing, G. (2014) The Precariat : the New Dangerous Class. London : Bloomsbury, $2^{\text {nd }}$ rev. edition.

Therborn, G. (2004) Between Sex and Power: Family in the World, Cambridge: Polity.

Tizro, Z. (2012) Domestic Violence: Women, Marriage and Islam. London: Routledge.

UN Women (2017) "Facts and Figures: Ending violence against Women" http://www.unwomen.org/en/what-we-do/ending-violence-against-women (downloaded 25/11/2017)

Walby, S. (2005) 'Improving the statistics on violence against women' Statistical Journal of the United Nations Economic Commission for Europe, 22(4): 193-216.

Walby, S. (2010) Globalization and Inequalities: Complexity and Contested Modernities, Thousand Oaks, Calif. and London: Sage.

Watts, C. and Zimmerman, C (2002) 'Violence against women: Global scope and magnitude.' The Lancet, 359 (9313): 1232-1237.

$\mathrm{Xu}, \mathrm{X}$, , F, Zhu, P O'Campo, M. A. Koenig, V.Mock, and J.Campbell, (2005) 'Prevalence of and Risk Factors for Intimate Partner Violence in China' American Journal of Public Health 95(1): 78-85.

Yount, K (2009) 'Women's “Justification” of Domestic Violence in Egypt'. Journal of Marriage and Family. 71(5): 1125-1140 